\title{
8
}
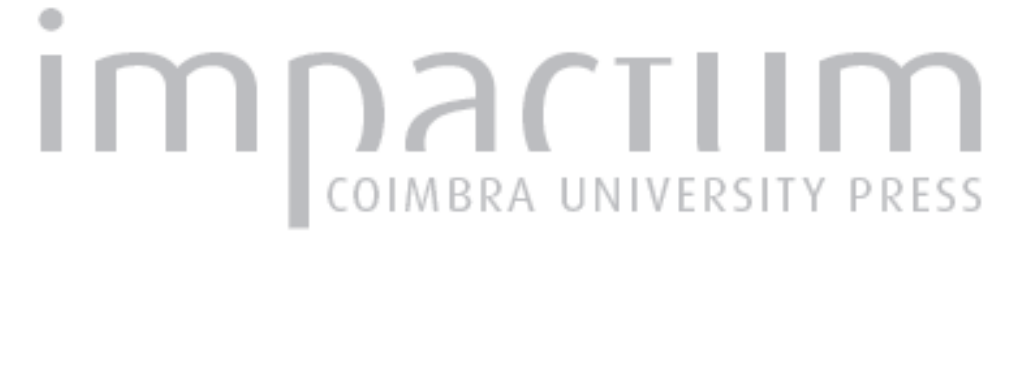

\section{Políticas públicas de preservação histórica: diagnóstico de risco dos imóveis tombados na cidade de Bauru/SP Brasil}

Autor(es): $\quad$ Losnak, Sérgio Ricardo; Lopes, Camila Santos Doubek

Publicado por: Associação Portuguesa de Riscos, Prevenção e Segurança; Imprensa

URL

persistente:

da Universidade de Coimbra

DOI: DOI:http://dx.doi.org/10.14195/1647-7723_22_18

Accessed : $\quad$ 26-Apr-2023 15:20:50

A navegação consulta e descarregamento dos títulos inseridos nas Bibliotecas Digitais UC Digitalis, UC Pombalina e UC Impactum, pressupõem a aceitação plena e sem reservas dos Termos e Condições de Uso destas Bibliotecas Digitais, disponíveis em https://digitalis.uc.pt/pt-pt/termos.

Conforme exposto nos referidos Termos e Condições de Uso, o descarregamento de títulos de acesso restrito requer uma licença válida de autorização devendo o utilizador aceder ao(s) documento(s) a partir de um endereço de IP da instituição detentora da supramencionada licença.

Ao utilizador é apenas permitido o descarregamento para uso pessoal, pelo que o emprego do(s) título(s) descarregado(s) para outro fim, designadamente comercial, carece de autorização do respetivo autor ou editor da obra.

Na medida em que todas as obras da UC Digitalis se encontram protegidas pelo Código do Direito de Autor e Direitos Conexos e demais legislação aplicável, toda a cópia, parcial ou total, deste documento, nos casos em que é legalmente admitida, deverá conter ou fazer-se acompanhar por este aviso. 


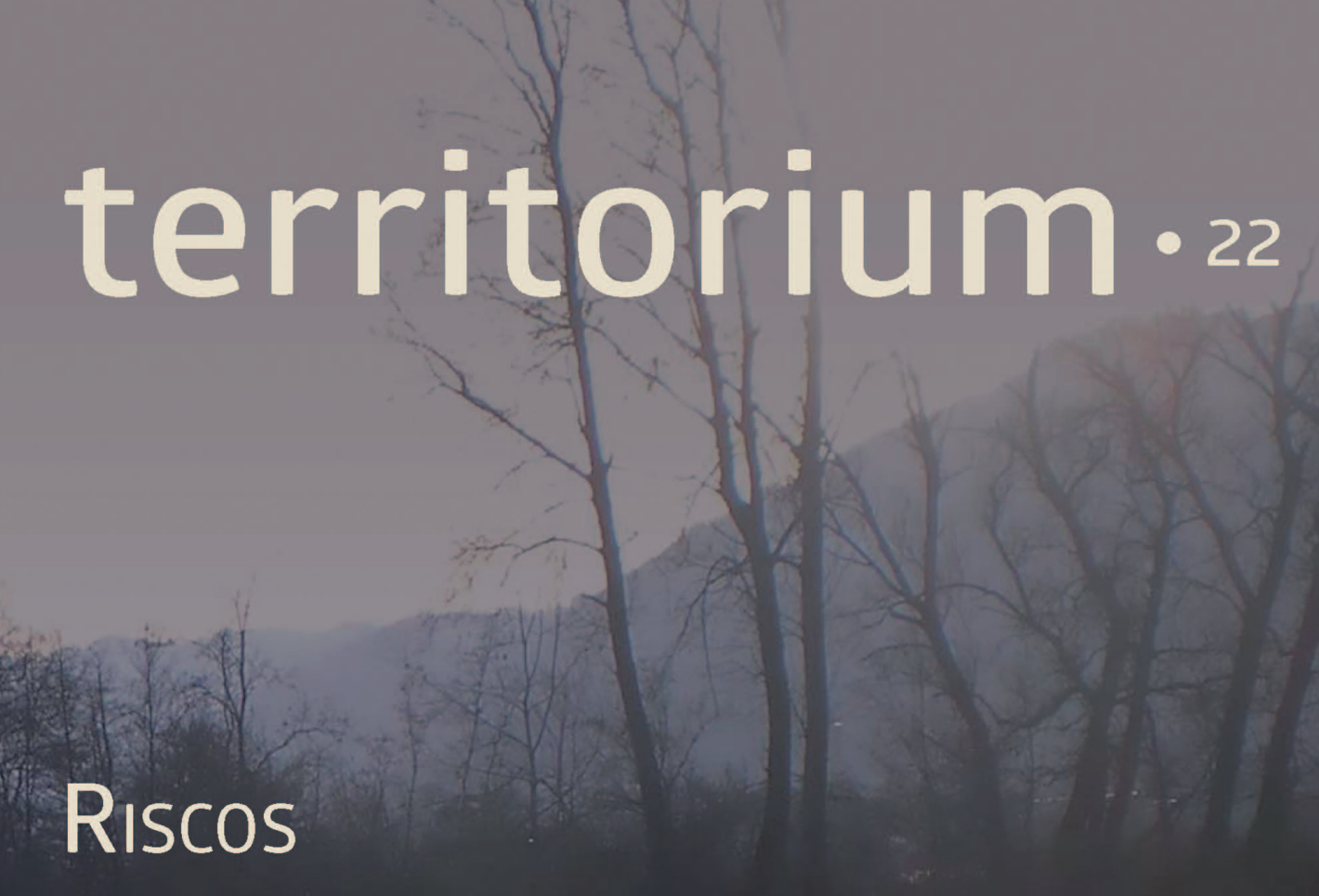

\section{TERRITÓRIOS DE CONVERGÊNCIA}

- Imprensa da Universidade de Coimbra Associação Portuguesa de:Riscos, Prevenção e Segurança 


\title{
POLÍTICAS PUBLICAS DE PRESERVAÇÃO HISTÓRICA: DIAGNÓSTICO DE RISCO DOS IMÓVEIS TOMBADOS NA CIDADE DE BAURU/SP BRASIL*
}

\author{
PUBLIC POLICY OF HISTORIC PRESERVATION: \\ RISK DIAGNOSIS OF THE PROTECTED BUILDINGS IN BAURU/SP BRAZIL
}

\author{
Sérgio Ricardo Losnak \\ Departamento de Arquitetura, FAAC da Universidade Estatual Paulista de Bauru \\ sergiolosnak@gmail.com \\ Camila Santos Doubek Lopes \\ Departamento de Geociências, CCE da Universidade Estadual de Londrina \\ uel.camila@gmail.com
}

\section{RESUMO}

Este trabalho objetiva diagnosticar os agentes de riscos que contribuem para a descaracterização do patrimônio histórico local e a relação existente entre preservação e a forma de uso e ou abandono. Para alcançar os resultados foi empregada pesquisa quali-quantitativa, bibliográfica exploratória e documental, assim como visitas técnicas a cada um dos bens. Os resultados alcançados mostram os agentes que contribuem para a descaracterização dos bens tombados, levando a conclusão que o fato de um bem estar tombado não garante a sua preservação.

Palavras-chave: Riscos, vulnerabilidade, tombamento, patrimônio histórico, Bauru/SP.

\section{ABSTRACT}

This study aims to diagnose the risk agents that contribute to the descaracterization of local heritage and the relationship between preservation and the form of use and or abandonment. To achieve the results was used qualitative and quantitative research, exploratory and documentary literature as well as technical visits to each of the buildings. The results achieved show the agents that contribute to the mischaracterization of listed buildings. The conclusion of the research is the fact that a well protected asset does not guarantee its preservation.

Keywords: Risks, vulnerability, tombamento, cultural patrimony, Bauru/SP.

\section{RESUMEN}

Políticas Publicas de preservación histórica: diagnóstico de riesgo de propiedades catalogadas en la ciudad de Bauru/SP Brasil - Este estudio tiene como objetivo diagnosticar los riesgos que contribuyen a la distorsión del patrimonio local y estudiar la relación existente entre la preservación y la forma de uso o de abandono. Para lograr los resultados se utilizó la investigación cualitativa y cuantitativa, la literatura exploratoria y documentales, así como visitas técnicas a cada uno de las propiedades. Los resultados obtenidos muestran que los agentes que contribuyen a la caracterización errónea de los edificios catalogados, lo que lleva a la conclusión de que una propiedad derribada no garantiza su preservación.

Palabras clave: Riesgos, vulnerabilidad, protección, patrimonio histórico, Bauru/SP.

\section{RÉSUMÉ}

La politique publique de conservation historique: diagnostic des risques des immeuble protégé à Bauru/SP Brésil - Ce travail vise à diagnostiquer les agents des risques qui contribuent à la mauvaise interprétation du patrimoine historique local et la relation existante entre la préservation et la façon d'utiliser et ou l'abandon. Pour atteindre les résultats, ont été utilisés recherche qualitative et quantitative, de la littérature d'exploration et documentaire. Il a été utilisé aussi des visites techniques à chacune des immobiles. Les résultats obtenus montrent les agents qui contribuent à la mauvaise interprétation du immobile protegéprotégé, conduisant à la conclusion que le fait qu'un bien être classé ne garantit pas leur conservation.

Mots-clé: Risques, vulnerabilité, protection, patrimoine historique, Bauru/SP.

* O texto deste artigo corresponde a uma comunicação apresentada no III Congresso Internacional, I Simpósio Ibero-Americano e VIII Encontro Nacional de Riscos, tendo sido submetido em 30-01-2015, sujeito a revisão por pares a 30-04-2015 e aceite para publicação em 08-07-2015.

Este artigo é parte integrante da Revista Territorium, n. ${ }^{\circ} 22,2015,{ }^{\circ}$ RIscos, ISSN: 0872-8941. 


\section{Introdução}

No Brasil, a política de preservação do patrimônio cultural é aplicada pelos poderes públicos, que possuem legislações e metodologias específicas e seguem as orientações da Constituição Federal e parcialmente das convenções internacionais. O mecanismo de tombamento é o principal recurso empregado para a preservação de um imóvel (BRASIL, 2014). No município de Bauru/SP, o tombamento se dá por ações do poder público municipal em conjunto com a sociedade civil, por meio do Conselho de Defesa do Patrimônio Cultural - CODEPAC.

Um bem histórico é aquele que recebe uma titulação pública e tem associado a ele reconhecimento de identidade de determinado grupo humano. As mediações no campo simbólico formadas por afetos, lembranças e memórias, quando se efetivam garantem ao bem determinado nível de preservação (Claval, 2007). Quanto à preservação, mais especificamente de bem material, busca-se a manutenção da sua integridade física e de suas características originais, ao mesmo tempo que se procura tornar o bem acessível às pessoas, colocando-o em uma dimensão pública e coletiva para se estabelecer as diferentes mediações inerentes ao sujeito e ao objeto (BRASIL, 2004).

Como consequência das forças hegemônicas do capital especulativo imobiliário somado à ineficiência do Estado no cumprimento das legislações que disciplinam o crescimento da cidade, têm-se o constante aumento da população nas cidades brasileiras, juntamente com seu crescimento desordenado, gerando ameaças e riscos à integridade do patrimônio cultural.

Os diferentes riscos e ameaças que os bens culturais estão sujeitos não são exclusivamente associado aos fatores físicos da geografia do lugar mas também aos fatores socioculturais e econômicos (BRASIL, 2013). Para tanto a gestão de risco é imprescindível e envolve diferentes áreas do conhecimento e de campo de atuação profissional, a sinaliza como proteger de fato os bens de relevância para a humanidade e manter estes espaços de reafirmação identitária de modo a assegurar o direito à memória cultural (Zanirato, 2010).

Em virtude da ausência de um diagnóstico preciso quanto à situação atual dos imóveis tombados, este trabalho propõe identificar os agentes de riscos que contribuem para a descaracterização do patrimônio histórico local e a relação existente entre preservação com a forma de uso e ou abandono.

Quanto à metodologia, foi realizada pesquisa qualiquantitativa, bibliográfica exploratória e documental em processos de tombamentos, atas e legislações pertinentes ao CODEPAC, além de visitas técnicas a cada um dos bens.

\section{Patrimônio histórico}

A construção dos sentidos relativos ao termo patrimônio cultural surge com a invenção da ideia de nação, no século XIX (Chauí, 2006) e está associado ao conjunto de monumentos, objetos, documentos e técnicas. “... semióforo é alguma coisa ou algum acontecimento cujo valor não é medido por sua materialidade e sim por sua força simbólica, por seu poder para estabelecer uma mediação entre o visível e o invisível, o sagrado e o profano, o presente e o passado, os vivos e os mortos e destinado exclusivamente à visibilidade e à contemplação, porque é nisso que realiza sua significação e sua existência".

A Carta Internacional de Veneza de 1964, ao estabelecer orientações quanto à conservação e restauro, esclarece que os monumentos somente se estabelecem como tal, a determinado grupo humano, quando são atribuídos a eles importantes e diversos significados simbólicos. 0 documento amplia o significado do bem cultural por meio de atribuições de sentidos simbólicos de caráter espiritual que vão sendo, com o tempo, construídos, modificados e solidificados tanto na memória distante como na memória presente e até mesmo na falta dela. 0 uso, conservação e manutenção das características originais do bem contribuem para a construção permanente da identidade do lugar e do grupo humano, assim, o uso é quando o bem se define como espaço de vivência.

"Art.6 - A conservação de um monumento implica a manutenção de um espaço envolvente devidamente proporcionado. Sempre que o espaço envolvente tradicional subsista, deve ser conservado, não devendo ser permitidas quaisquer novas construções, demolições ou modificações que possam alterar as relações volumétricas e cromáticas" (ICOMOS, 1964).

A ideia de patrimônio cultural associado aos semióforos estabelece determinada hierarquização de objetos. Há aqueles considerados inferiores, que têm valor associado a seu uso. Já os com valores simbólicos superiores, os semióforos, são dotados de prestigio e poder. Os primeiros detentores dos semióforos foram as chefias religiosas e o Estado. Pode-se compreender na contemporaneidade, que os sentidos inerentes de hierarquia dos semióforos produzem aos bens culturais um isolamento necessário exclusivamente para sua contemplação, se tornando um elemento de prestigio e poder ao seu detentor, alimentando a superioridade de determinadas classes e ao poder político. Nesta situação, o bem tem seu sentido simbólico consolidado, não sendo permitidas resignificações para a manutenção do seu valor.

Os elementos de análise deste trabalho quanto ao uso e à conservação estão relacionados ao discurso crítico de Junior (2007), quanto à necessidade do patrimônio histórico estar se resignificando, não só em seus sentidos 
simbólicos construídos pelo grupo humano o qual ele pertence, mas integrando seu uso às atividades práticas da vida em cada temporalidade. O bem é colocado permanentemente em mutação, sua transformação orgânica tanto física como simbólica é sua própria existência, se tornando capaz de existir, de diferir e de divergir. "Preservar não é congelar numa pose uma certa temporalidade.... Aqueles elementos de patrimônio que não foram reinvestidos de significado para a sociedade a que pertencem que não foram reapropriados e resignificados pelas gerações, tornandose ruínas físicas ou, pior, ruínas de sentido, como aquele lindo monumento em torno do qual todo mundo circula, mas não conhece a sua história ou com que sentido foi construído, aquela estátua que serve apenas de depósito de fezes de pombos" (Junior, 2007).

\section{As cidades e o tombamento}

Na perspectiva da dimensão do tempo e do espaço, a formação de uma cidade se configura como natureza transformada. Lugares são instituídos, bens são construídos de forma a possibilitar a ocupação humana, desde que ofereça aos seus indivíduos condições essenciais de sobrevivência e elementos que contribuam para a construção de uma identidade coletiva em diferentes tempos (Claval, 2007)

“O tempo e os espaços, são pois dimensões para analisar o fenômeno urbano, referenciais que possuem sentido e que são ligados a si: cada recorte de território, cada forma, cada matéria contém uma temporalidade que remete a atores, a praticas sociais e a significações. Do mesmo modo, cada momento do passado deixa marcas objetivas no espaço" (Pesavento, 2012).

L. Benévolo (1993), quando descreve as particularidades das cidades pós-liberais, indica que estas se sobrepõem às cidades mais antigas e tende a destruí-las. Este processo gera uma contradição entre o novo e o velho e entre as diferentes formas de uso, provocando fragmentação do espaço, que descaracteriza a identidade. Para o cidadão, o real usuário da cidade, esta situação provoca um impacto visual de forma negativa, pouco atraente. A cidade passa a não atender as demandas práticas da vida, se torna um ambiente menos significativo e consequentemente menos humano.

“A presença dos monumentos antigos e estilizados dos manufaturados modernos não bastam para compensar completamente os desequilíbrios da cidade. A feiura do ambiente normal aparece irremediável; por isso a experiência da beleza se torna algo excepcional..." (Benévolo, 1993).

No imaginário coletivo, de uma forma geral, se solidifica a ideia de que tombamento é o congelamento do bem, que nenhuma alteração poderá ser feita, nem mesmo adaptações que possam atender as novas demandas de uso, acessibilidade e conservação. Este entendimento provoca um distanciamento das práticas cotidianas de vida com as formas e possibilidade de uso do bem.

Abordagem histórica das políticas públicas de proteção ao patrimônio no Brasil

As primeiras ações culturais de Estado implementadas no Brasil se referem ao período em que Dom João VI com sua corte transferem a sede da Coroa Portuguesa em 1808 para o Brasil. Na antiga colônia a nobreza portuguesa encontrou uma sociedade significativamente rústica comparada à europeia, fato que fez com que Dom João implementasse ações de formação cultural de seus súditos, criando importantes equipamentos culturais como o Instituto Histórico e Geográfico do Brasil, Academia Imperial de Belas Artes, Biblioteca Nacional e Museu Nacional. Desta forma a Coroa se coloca como produtor de cultura e marca o inicio da atuação do Estado Brasileiro como produtor da cultura elitista.

As políticas culturais propriamente ditas que tratam da preservação do patrimônio cultural no Brasil se iniciam quando Gustavo Campanema assume o Ministério da Educação e Saúde no Governo de Getúlio Vargas (19341945) e juntamente com Mário de Andrade criam em 1937 o SPHAN - Serviço do Patrimônio Histórico e Artístico Nacional. Esta política ficou conhecida como preservação de pedra e cal, alusão ao teor monumental para a preservação. Com o passar dos anos o SPHAN foi transformado em instituto do Patrimônio Histórico e Artístico Nacional - IPHAN - e foi acompanhando modestamente as diretrizes internacionais de preservação. Um dos grandes avanços na política nacional de preservação se deu com a ampliação do conceito de bens culturais. Os artigos 215 e 216 da Constituição Federal de 1988 passam a reconhecer os bens de natureza imaterial, como patrimônio cultural. No Brasil, de acordo com o IPHAN, a preservação de bens materiais e imateriais pode ser garantida pelo mecanismo de tombamento, que pode se dar por ato administrativo, por meio de legislação específica nos três níveis do executivo, federal, estadual ou municipal (Rubim, 2007).

\section{Preservação e risco}

Historicamente, a gênese do risco se deteve a proporcionar as pessoas, segurança diante de eventos ligados a dinâmica da natureza. Já num passado mais próximo os agentes de riscos gerados pelo modelo de vida produtivo que se materializa na organização urbana caótica, coloca a ação humana na mesma dimensão de riscos que a natural. As dimensões se fundem e homem e natureza se tornam causadores de perigo e insegurança. 
Segundo Amaro (2003), um dos grandes produtores de perigo é o "egocentrismo", que é a uma particularidade humana que se efetiva quando da falta de vigilância frente às ações exteriores. No contexto de nossa pesquisa, o patrimônio histórico definha constantemente dentro da ótica de Amaro (2003). Os bens tombados se tornam única e exclusivamente uma responsabilidade do proprietário, apesar de possuírem um título publico de reconhecimento histórico e de importância na manutenção da identidade cultural da cidade. Tanto o poder público como a população que convive com os bens não demonstram o sentimento de pertencimento a história deste patrimônio, assim se eximem de suas responsabilidades.

\section{Objeto de estudo: a cidade de Bauru}

Bauru teve sua formação inicial no período de desbravamento do interior do Estado de São Paulo. Seu embrião urbano nutria e garantia segurança para as ocupações de terras rumo ao oeste do estado por volta da segunda metade do século XIX. Em terras dos índios Kaingangues, o arraial árido, mais tarde conhecido como a Capital da Terra Branca, se transformou em município em 1896 e no ano de 1901 contava com 7.815 habitantes, em sua maioria vivendo em fazendas. 0 papel do urbano nestes tempos era de concentrar as atividades econômicas, serviços e comércio. No caso de Bauru, a grande estrutura de transporte ferroviário implantada no início do século XX servia para atender as demandas da produção de café. Definia-se desta forma sua característica de polarização regional, em virtude de suas atividades como urbe. A ocupação humana se deu com a vinda de fazendeiros de Minas Gerais que buscavam terras para se apossarem e implantar suas fazendas. Mais tarde começaram a chegar os imigrantes que aumentavam as frentes de trabalho rural. (Bauru, 1997).

Como frente e suporte para ocupação do oeste, Bauru se tornou "chão de passagem" (Sant 'Agostinho, 1995), principalmente pela construção da Estrada de Ferro Noroeste do Brasil - EFNOB em 1905, que parte de Bauru e chega em Corumbá, Estado do Mato Grosso Sul, divisa territorial com a Bolívia. $O$ apelido também se deve pela chegada dos trilhos de mais duas ferrovias que ligava a cidade ao Porto de Santos, a Estrada de Ferro Sorocabana (1904) e Estrada de Ferro da Companhia Paulista (1911) (Silva, 1957).

A cidade de Bauru abriga edificações expressivas com estilos variados como eclético, art deco e moderno, que se associam ao patrimônio industrial ferroviário, bem como, aqueles que foram construídos com a finalidade de atender as demandas indiretas relativas ao transporte. Atualmente, parte dos edifícios da região central se encontram tombados pelo CONDEPHAAT - Conselho de Defesa do Patrimônio Histórico, Arqueológico, Artístico e Turístico do Estado de São Paulo - e CODEPAC Conselho de Defesa do Patrimônio Cultural de Bauru, mesmos assim, requerem cuidados e políticas que vão ao encontro das orientações colocadas pela Carta de Nizhny Targil, que reconhecem o patrimônio industrial como representações identitárias (ICOMOS, 2003).

\section{O CODEPAC}

Criado em 1992, com característica consultiva, é composto por membros da sociedade civil e do executivo. A Lei $n^{\circ}$ 4.558, de 21 de junho de 2000, define a seguinte representação: Secretaria dos Negócios Jurídicos; Secretaria de Planejamento; Secretaria de Cultura; Departamento de Proteção Cultural da Secretaria de Cultura; Ordem dos Advogados do Brasil; Associação Amigos dos Museus; Associação dos Geógrafos Brasileiros; Associação dos Engenheiros, Arquitetos e Agrônomos; Instituto de Arquitetos do Brasil; Universidade do Sagrado Coração; UNESP e Câmara Municipal (CODEPAC, 2014).

Os procedimentos administrativos para efetivação do tombamento são estabelecidos pelo Decreto Municipal $n^{\circ} 9.250 / 2002$, o qual atribui ao CODEPAC à função de indicar a dimensão do tombamento de um bem, ou seja, o que deve ser preservado e o que pode ser alterado, além da elaboração de laudos e pareceres que possam embasar a decisão definitiva de tombamento. Porém as indicações do CODEPAC se efetivam quando da elaboração e publicação do Decreto de Tombamento por parte do líder do executivo, que tem a prerrogativa de incluir e ou suprimir tais propostas (CODEPAC, 2014).

Por meio de análise dos Decretos de Tombamento dos bens imóveis, em geral, as preservações se restringem as fachadas e volumetria. Em apenas um deles a preservação é integral: Igreja Presbiteriana. Outros dois apresentam a preservação de outros elementos internos, como o hall de entrada e a gare da Estação da NOB e o hall de entrada, escadaria e o vitral do Automóvel Clube. Nos documentos pesquisados não foi possível identificar quais são os critérios utilizados pelo CODEPAC para definição pelo tombamento integral ou parcial do bem, o que foi possível evidenciar é que a política preservacionista praticada não leva em conta as orientações nacionais e internacionais, principalmente quanto sua integralidade e seu entorno (CODEPAC, 2014).

\section{Mecanismos legais}

A gestão do patrimônio cultural está associado às políticas públicas estabelecidas nas três instancias do Estado, mas é no município que de fato a preservação se efetiva. Assim, cabe a ele a implantação de políticas públicas relacionas à outros dispositivos de planejamento 
da cidade, com envolvimento da sociedade civil e da prática sistêmica de educação patrimonial aos diferentes públicos que formam a cidade.

A preservação do patrimônio cultural de Bauru é composta por instrumentos legais em vigor, que serão descritos a seguir.

A Lei Municipal $n^{\circ}$ 3.486, de 24 de agosto de 1992 cria o Conselho de Defesa do Patrimônio Cultural de Bauru, CODEPAC atribuindo suas funções, objetivos, competências e dimensiona o efeito do tombamento. Define procedimentos para intervenções no bem, impõe penalidades e estabelece o rito de procedimentos para se efetivar o tombamento. A lei também define sua composição, com representantes da sociedade civil e poder público municipal, item que foi alterado pela Lei $\mathrm{n}^{\circ} 4.558$, de 21 de junho de 2000 (CODEPAC, 2014).

O Decreto $n^{\circ} 7.579 / 96$ disciplina o funcionamento do CODEPAC por meio do Regimento Interno (CODEPAC, 2014).

O Decreto $n^{\circ}$ 9.250, de 16 de agosto de 2002 que regulamenta a Lei Municipal $\mathrm{n}^{\circ} 3.486$, de 24 de agosto de 1992, estabelece diretrizes para nomeação dos membros, trata dos efeitos do tombamento, das intervenções do bem, das edificações vizinhas, do entorno e do atrelamento do Conselho à estrutura administrativa e financeira da Secretaria Municipal de Cultura (CODEPAC, 2014).

A Lei $\mathrm{n}^{\circ}$ 6.248, de 16 de agosto de 2012. Concede isenção parcial de Imposto Predial e Territorial Urbano - IPTU -, sendo de $75 \%$ na hipótese de tombamento do imóvel na sua integralidade e $50 \%$ na hipótese de tombamento da fachada. A concessão é concedida mediante a comprovação da conservação do imóvel. $\mathrm{Na}$ tramitação deste projeto de lei na Câmara, um fato criou divergência entre os poderes: uma emenda parlamentar foi apresentada, aprovada e incluída na lei estipulando a obrigatoriedade da aprovação legislativa prévia de qualquer tombamento de imóvel no município, conforme Artigo $2^{\circ}$ da referida lei. $\mathrm{Na}$ prática a prerrogativa do tombamento ficou transferida do poder executivo para o legislativo. Assim, seguindo os ritos legais, o executivo promulgou a lei, com veto ao Artigo $2^{\circ}$, alegando inconstitucionalidade. 0 veto foi derrubado e a Câmara promulgou a lei, conforme sua aprovação. Sua regulamentação foi realizada por meio do Decreto $\mathrm{n}^{\circ} 12.123$, de 18 de abril de 2013 (CODEPAC, 2014).

A Lei $n^{\circ} 6.317$, de fevereiro de 2013 , autoriza a realização de alterações nos imóveis para fim de acessibilidade à portadores de deficiência física. 0 bem pode sofrer qualquer alteração, adaptação e mutilação, sem que o Conselho avalie e opine, desde que sejam respeitadas as normas técnicas de acessibilidade definidas pela ABNT (CODEPAC, 2014).

\section{Metodologia de pesquisa}

Para este trabalho foi feita pesquisa bibliográfica exploratória, documental, com abordagem quantiqualitativa (Gil, 2002). Inicialmente foi realizado o embasamento teórico bibliográfico exploratório para maior compreensão sobre os temas inerentes à pesquisa. Posteriormente foi feito o levantamento da legislação municipal referente à preservação do patrimônio cultural no município nos arquivos da Secretaria Municipal dos Negócios Jurídicos. Também foram examinadas as Atas do CODEPAC e os Processos de Tombamento, arquivados no Museu Histórico Municipal de Bauru. A última etapa metodológica foi a realização da pesquisa in situ, ou seja, visitas técnicas aos imóveis tombados, que permitiu um diagnóstico amplo sobre a situação da preservação dos 35 imóveis tombados no município. Dentre os bens tombados, e em estudo de tombamento encontram-se imóveis, bens rodantes ferroviários e o acervo tridimensional do Museu Ferroviário Regional. Este trabalho se delimitou ao universo de 35 bens imóveis, que efetivamente se encontram tombados por meio de Decreto Municipal.

\section{Resultados}

Os resultados provenientes desta pesquisa se originam por meio de duas vertentes que se relacionam diretamente. A primeira se dá pela identificação dos agentes de riscos que os bens estão expostos atualmente, e a segunda se dá pela efetividade da preservação das características originais dos bens, tendo em vista seu uso e ou a falta de uso (abandono). Desta forma estes resultados nos indicam a atual situação de vulnerabilidade da qual este bens estão expostos.

Por meio da realização de um comparativo entre a situação atual dos bens tombados e aquela na qual se encontrava no momento de abertura do seu processo de tombamento, foram analisadas as seguintes condicionantes que compõem a TABELA I: (i) identificação do bem; (ii) uso atual: indica se o bem encontrase em uso, e se este uso está associado à finalidade para o qual o imóvel foi projetado; (iii) estado de conservação: indica o nível de conservação, levando em conta os cuidados e zelos dedicados ao bem, como limpeza, pintura e restauro, sendo que para este item foi estabelecido três níveis: bom, regular e ruim; (iiii) estado de descaracterização: indica se o bem está preservado nas suas características originais, ou foi parcialmente ou totalmente descaracterizado. Neste caso são considerados parcialmente descaracterizados aqueles bens que perderam algum importante elemento arquitetônico original e os descaracterizados são aqueles que encontram-se mutilados. 
A TABela I, também apresenta uma coluna entitulado "Riscos". Os números que estão associados a esta coluna se referem aos itens de agentes de riscos, definidos na tabela seguinte (TABELA II - Agentes de risco).
Sintetizando os resultados, encontrou-se a seguinte situação: dos 35 imóveis estudados, 26 (74\%) apresentam ocupação total de suas dependências; 3 (9\%) possuem ocupação parcial e; 6 (17\%) estão

TABELA I - Situação do bem tombado.

TABLE I - The situation of the protected building.

\begin{tabular}{|c|c|c|c|c|}
\hline \multicolumn{5}{|c|}{ BENS TOMBADOS EM USO } \\
\hline Bem & Uso atual & Conservação & Descaracterização & Riscos \\
\hline Hotel Cariani & Hotel & Bom & Ausente & $1 ; 2 ; 3 ; 5 ; 6$ \\
\hline Hotel Estoril & Hotel & Ruim & Parcial & $1 ; 2 ; 3 ; 5 ; 6$ \\
\hline Casa Comercial - Sobrado do Calçadão & Comércio & Bom & Ausente & $1 ; 2 ; 3 ; 6$ \\
\hline Antigo Palacete Pagani & Comércio & Bom & Ausente & $1 ; 2 ; 3 ; 6$ \\
\hline Antigo Grupo Escolar Ernesto Monte & Comércio & Ruim & Parcial & $1 ; 2 ; 3 ; 5 ; 6$ \\
\hline Antiga Casa Savastano & Comércio & Ruim & Parcial & $1 ; 2 ; 3 ; 5 ; 6$ \\
\hline Antiga Farmácia Popular & Comércio & Regular & Ausente & $1 ; 2 ; 3 ; 6$ \\
\hline Antiga Casa Lusitana & Comércio & Regular & Parcial & $1 ; 2 ; 3 ; 6$ \\
\hline Edifício Brasil-Portugal & Moradia & Regular & Ausente & $1 ; 2 ; 3 ; 5 ; 6$ \\
\hline Edifício Abelha & Moradia & Bom & Ausente & $1 ; 2 ; 3 ; 6$ \\
\hline Sede da Fazenda Divisa & Moradia & Regular & Ausente & $1 ; 2 ; 3 ; 6$ \\
\hline Sede da Fazenda Val de Palmas & Moradia & Regular & Parcial & $1 ; 2 ; 3 ; 6$ \\
\hline Igreja Santa Teresinha & Igreja & Regular & Ausente & $1 ; 2 ; 3 ; 6$ \\
\hline Igreja Presbiteriana Independente & Igreja & Regular & Parcial & $1 ; 2 ; 3 ; 6$ \\
\hline Capela da Santa Casa De Misericórdia & Igreja & Bom & Ausente & $1 ; 2 ; 3 ; 6$ \\
\hline Igreja Tenrikyo & Igreja & Bom & Ausente & $1 ; 2 ; 3 ; 6$ \\
\hline Antiga Casa do Superintendente da NOB & Escritório & Bom & Parcial & $1 ; 2 ; 3 ; 5 ; 6$ \\
\hline Antiga PRG-8 (atual TV TEM) & Escritório & Bom & Ausente & $1 ; 2 ; 3 ; 6$ \\
\hline Casa Aliança Francesa & Escritório & Bom & Parcial & $1 ; 2 ; 3 ; 5 ; 6$ \\
\hline Portal de entrada do Cemitério da Saudade & Escritório & Regular & Ausente & $1 ; 3 ; 6$ \\
\hline Aeroclube de Bauru & Escritório e hangares & Ruim & Parcial & $1 ; 2 ; 3 ; 6$ \\
\hline Fachada da Beneficência Portuguesa & Hospital & Bom & Parcial & $1 ; 2 ; 3 ; 6$ \\
\hline Automóvel Clube de Bauru - Público & Sede da Orquestra & Bom & Ausente & $1 ; 2 ; 3 ; 6$ \\
\hline Grupo Escolar Rodrigues de Abreu & Escola particular & Bom & Parcial & $1 ; 2 ; 3 ; 5 ; 6$ \\
\hline Palácio das Cerejeiras - Público & Prefeitura Municipal & Regular & Parcial & $1 ; 2 ; 3 ; 6$ \\
\hline Quartel Militar - Público & Policia Militar & Bom & Ausente & $1 ; 2 ; 3 ; 6$ \\
\hline \multicolumn{5}{|c|}{ BENS TOMBADOS PARCIALMENTE EM USO } \\
\hline Estação Val de Palmas & $\begin{array}{l}\text { Desocupado/ } \\
\text { Invadido }\end{array}$ & Ruim & Parcial & $1 ; 2 ; 3 ; 5 ; 6$ \\
\hline Sede INSS & $\begin{array}{l}\text { Desocupado/ } \\
\text { Escritório }\end{array}$ & Ruim & Ausente & $1 ; 2 ; 3 ; 6$ \\
\hline Estação da Cia Paulista & $\begin{array}{l}\text { Desocupado/ Em } \\
\text { obra }\end{array}$ & Ruim & Ausente & $1 ; 2 ; 3 ; 5 ; 6$ \\
\hline \multicolumn{5}{|c|}{ BENS TOMBADOS SEM USO } \\
\hline Casas Geminadas do começo do Séc. XX. & Desocupado & Ruim & Parcial/critico & $1 ; 2 ; 4 ; 5 ; 6$ \\
\hline Antigo Hotel Milaneze & Desocupado & Ruim & Ausente & $1 ; 2 ; 4 ; 5 ; 6$ \\
\hline Estação Central da EFNOB & Desocupado & Ruim & Ausente & $1 ; 2 ; 4 ; 5 ; 6$ \\
\hline Estação de Tibiriçá & Desocupado & Ruim & Parcial & $1 ; 2 ; 4 ; 5 ; 6$ \\
\hline Estação Sorocabana & Desocupado & Ruim & Ausente & $1 ; 2 ; 4 ; 6$ \\
\hline Estação Curuçá & Desocupado & Ruim & Parcial/critico & $1 ; 2 ; 4 ; 5 ; 6$ \\
\hline
\end{tabular}


totalmente desocupados. Considerando o uso dos 26 imóveis ocupados, constatou-se que a maioria, 23 (88\%) desempenham a função para a qual foram projetados e 3 (12\%) abrigam outras funções de uso.
Quanto ao estado de conservação dos imóveis, se apurou que 13 (37\%) se encontram bem conservados, 9 (26\%) em estado regular e 13 (37\%) não apresentam algum tipo de conservação, comprometendo a preservação de suas características originais.

TABeLA II - Agentes de risco.

TABLE II - Risk agents.

\begin{tabular}{|c|c|c|c|}
\hline ITEM & RISCOS & CAUSAS & CONSEQUENCIA \\
\hline 1 & 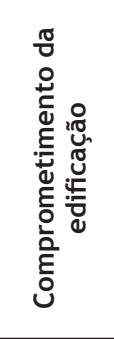 & $\begin{array}{l}\text { Falta de conservação dos bens } \\
\text { Intervenções inadequadas } \\
\text { Uso de materiais diferentes aos originais } \\
\text { Alteração na volumetria } \\
\text { Alterações das esquadrias } \\
\text { Vibrações causadas pelo tráfego de veículos e trens } \\
\text { Ataques de insetos (cupim, broca, pomba) } \\
\text { Desgaste natural pela intempérie }\end{array}$ & $\begin{array}{l}\text { Perda total ou parcial do bem } \\
\text { Perda das características originais do bem } \\
\text { Perda da ambiência e transformação do } \\
\quad \text { entorno } \\
\text { Perda de referências culturais }\end{array}$ \\
\hline 2 & 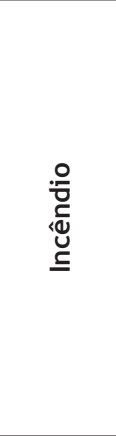 & $\begin{array}{l}\text { Conservação inadequada das edificações } \\
\text { Ausência de estrutura e plano de combate a incêndios } \\
\text { Falta de conservação da rede elétrica } \\
\text { Ausência de vistorias e acompanhamento do estado } \\
\text { do bem } \\
\text { Transporte de combustíveis por trens } \\
\text { Manobras e estacionamento de vagões de } \\
\text { combustíveis. } \\
\text { Acumulo de materiais e resíduos que possam propagar } \\
\text { fogo } \\
\text { Ocupação irregular }\end{array}$ & $\begin{array}{l}\text { Risco de vidas } \\
\text { Perda total ou parcial do bem } \\
\text { Perda das características originais do bem }\end{array}$ \\
\hline 3 & 옥 & $\begin{array}{l}\text { Alterações, ampliações e adaptações estruturais } \\
\text { Falta de manutenção permanente } \\
\text { Acumulo de resíduos e lixo } \\
\text { Desconhecimento das referências históricas do bem } \\
\text { Desconhecimento das normas, regulamentações e } \\
\text { políticas de uso de bem tombado }\end{array}$ & $\begin{array}{l}\text { Comprometimento em virtude da } \\
\text { ausência de consciência sobre a } \\
\text { relevância do bem } \\
\text { Perda de referências culturais } \\
\text { Construção de imagem negativa da } \\
\text { gestão local do patrimônio }\end{array}$ \\
\hline 4 & $\begin{array}{l}\stackrel{0}{c} \\
\stackrel{0}{0} \\
\frac{0}{0} \\
\stackrel{0}{<}\end{array}$ & $\begin{array}{l}\text { Desconhecimento da possibilidade de adaptação do } \\
\text { bem para outros usos } \\
\text { Custo elevado da restauração } \\
\text { Falta de política de estimulo a ocupação } \\
\text { Desvalorização imobiliária }\end{array}$ & $\begin{array}{l}\text { Ocupação irregular } \\
\text { Degradação com ação do tempo } \\
\text { Depredação }\end{array}$ \\
\hline 5 & 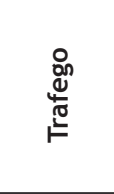 & $\begin{array}{l}\text { Concentração do transporte coletivo por ônibus no } \\
\text { centro da cidade } \\
\text { Transporte de carga seca e combustíveis por trens }\end{array}$ & $\begin{array}{l}\text { Vibrações que desagregam estruturas } \\
\text { edificadas } \\
\text { Poluição sonora } \\
\text { Possibilidade de acidente e } \\
\quad \text { descarrilamento }\end{array}$ \\
\hline 6 & 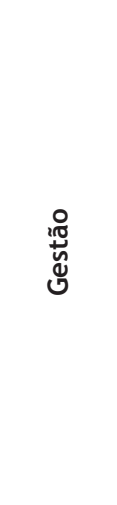 & $\begin{array}{l}\text { Legislação e regulamentação ineficiente quanto } \\
\text { aplicabilidade } \\
\text { Ausência de Plano de gestão do patrimônio cultural } \\
\text { Falta de fiscalização efetiva } \\
\text { Ausência de educação patrimonial } \\
\text { Ausência de inventário } \\
\text { Ausência de plano de risco } \\
\text { Inexistência da participação popular nos colegiados } \\
\text { de gestão } \\
\text { Conselhos de defesa do patrimônio consultivos } \\
\text { Falta de procedimentos públicos que auxiliem } \\
\text { proprietários quanto ao uso, conservação e } \\
\text { restauração do bem. }\end{array}$ & $\begin{array}{l}\text { Abandono } \\
\text { Falta de apropriação, pertencimento e } \\
\text { identificação simbólica do bem pela } \\
\text { coletividade } \\
\text { Alterações e modificações estruturais dos } \\
\text { bens por falta de desconhecimento e } \\
\text { técnica adequada } \\
\text { Desconstrução da identidade originária } \\
\text { da cidade } \\
\text { Atuação sem restrição da especulação } \\
\text { imobiliária } \\
\text { Conselho sujeito a interferência do poder } \\
\text { público }\end{array}$ \\
\hline
\end{tabular}


Quanto aos indícios de alterações das características originais dos imóveis, 19 (54\%) não apresentam sinais significativos de descaracterização, porém os outros 16 (46\%) apresentam intensas alterações. Outro resultado relevante aponta que, $66,7 \%$ dos bens parcialmente ou totalmente desocupados se referem às Estações Ferroviárias.

A visita técnica realizada a cada um dos bens proporcionou, por meio da observação, identificar os agentes que oferecem algum tipo de risco à preservação, bem como, suas possíveis causas e consequências, pois estes estão associados ao comprometimento estrutural e arquitetônico, incêndio, uso, abandono, trafego e a gestão publica patrimonial. Dentre estes riscos, alguns são comum a todos os bens, outros são mais específicos, pois estão relacionados a sua localização geográfica.

Como forma de aprofundamento da questão apresentada, optou-se em sistematizar os riscos identificados, de forma linear e não hierárquica, apontando causas e consequências diante do nível de preservação na qual cada bem se encontra, como se pode observar na TABELA II

Os fatores relacionados ao comprometimento estrutural do bem são todos aqueles que de alguma forma interferem em suas características originais e alteram sua estrutura arquitetônica e volumétrica (fig. 1). A técnica de construção, tipos de materiais utilizados e falta de conservação, são fatores significativos que atuam por meio deste agente de risco. Os pontos relacionados à força da natureza, tendo em vista a geografia da região, estão relacionados às intempéries. Um dos imóveis, Estação EFNOB, esta localizado em área de inundação, agravando sua situação de risco estrutural.

A possibilidade de risco de incêndio é comum a todos os imóveis, porém com graus distintos. 0 transporte de combustível por trem que ocorre as margens dos diversos prédios históricos é um dos fatores de maior risco (fig. 2). Materiais servíveis e inservíveis acumulados dentro e fora dos imóveis, que contribuem para propagação do fogo foram identificados em diversos bens (fig. 3).

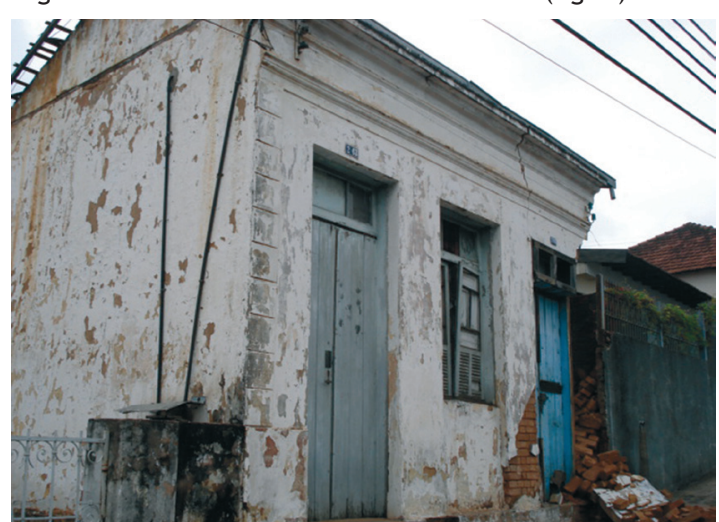

Fig. 1 - Casa dos Pioneiros, contendo degradação estrutural (Sérgio Losnak, 22/08/2014).

Fig. 1 - House of the Pioneers, having strutural degradation (Sérgio Losnak, 22/08/2014).

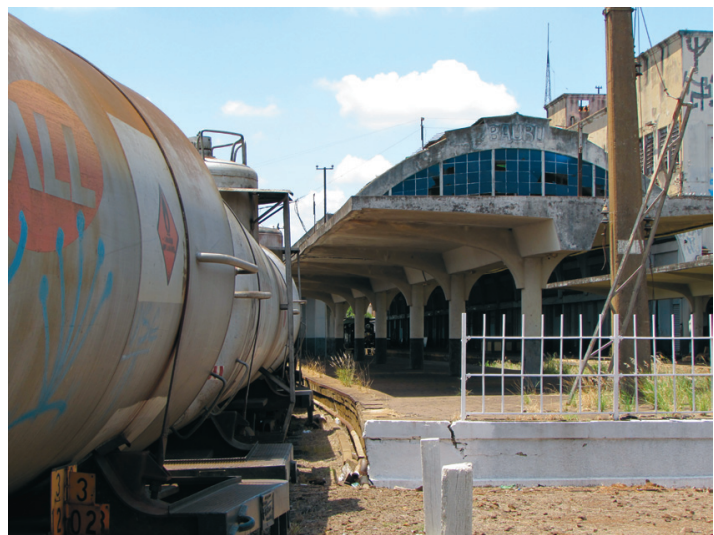

Fig. 2 - Transporte de combustível na Estação Ferroviária da EFNOB (Sérgio Losnak, 19/08/2014).

Fig. 2 - Transport of fuel at the EFNOB Railway Station (Sérgio Losnak, 19/08/2014).

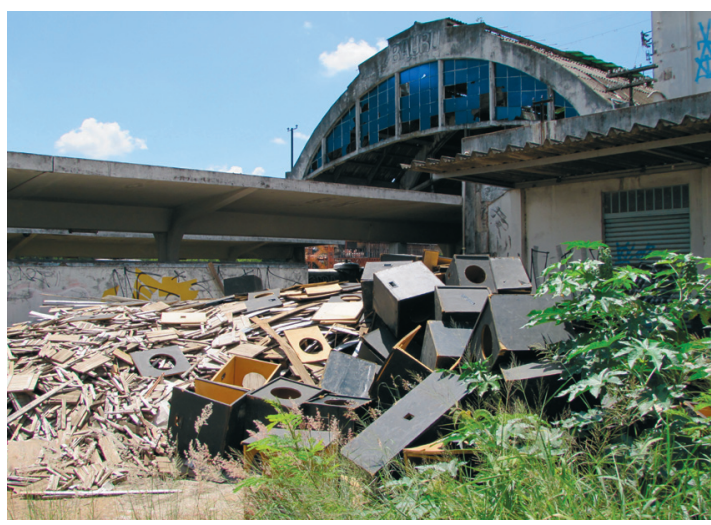

Fig. 3 - Materiais inservíveis depositados na Estação Ferroviária da EFNOB (Sérgio Losnak, 19/08/2014).

Fig. 3 - Useless materials deposited at the EFNOB Railway Station (Sérgio Losnak, 19/08/2014).

As alterações mais comuns encontradas nos bens tombados em uso foram relativas às esquadrias, pintura, volumetria e área envoltória (fig. 4).

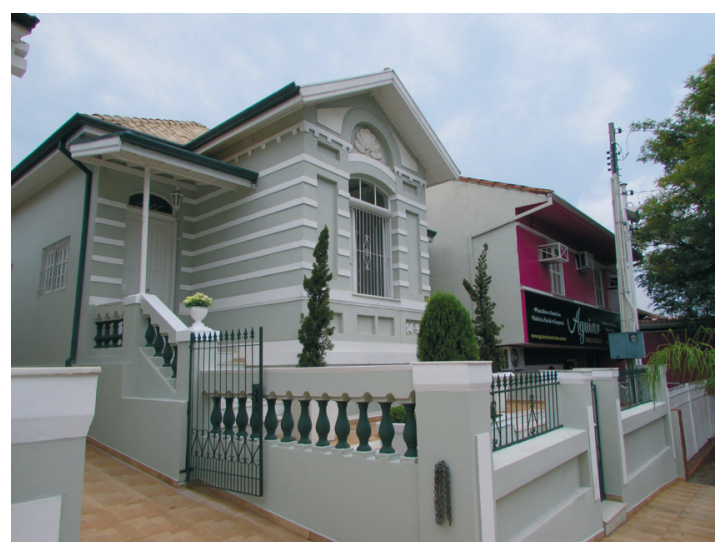

Fig. 4 - Casa Aliança Francesa. Descaracterização por uso (Sérgio Losnak, 22/08/2014).

Fig. 4 - House of French Alliance. Mischaracterization by use (Sérgio Losnak, 22/08/2014). 
O estado de abandono, ou a ausência formal de uso, intensifica a degradação natural e aumenta a ocorrência de ocupações irregulares permanentes ou temporária que aumentam em alto grau o risco de alterações e depredações do bem (fig. 5).

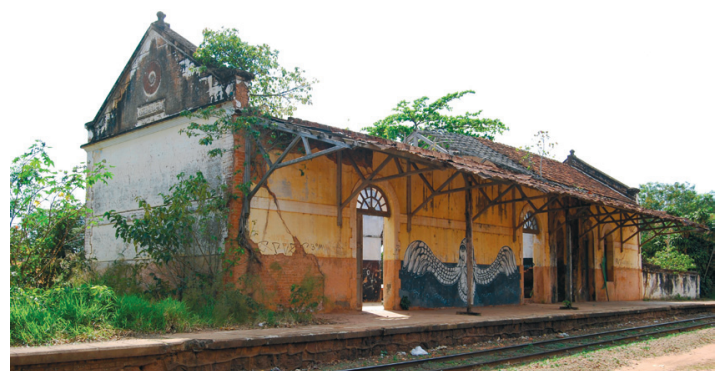

Fig. 5 - Estação Ferroviária Tibiriça, degradada por abandono (Sérgio Losnak, 27/08/2014).

Fig. 5 - Tibiriça Railway Station, mischaracterized by abandonment (Sérgio Losnak, 27/08/2014).

0 trafego de veículo que impacta no bem tombado pode ser divido em 3 níveis. 0 primeiro é aquele que se localiza em rua simples com pouco fluxo e à predominância de veículos leves, o segundo nível é aquele em ruas e avenidas com rotas de ônibus urbano (figs. 6 e 7) e o último esta associado a proximidade da linha férrea, (fig. 8) que em virtude das péssimas condições da malha ferroviária apresenta alto índice de descarrilamento de composições.

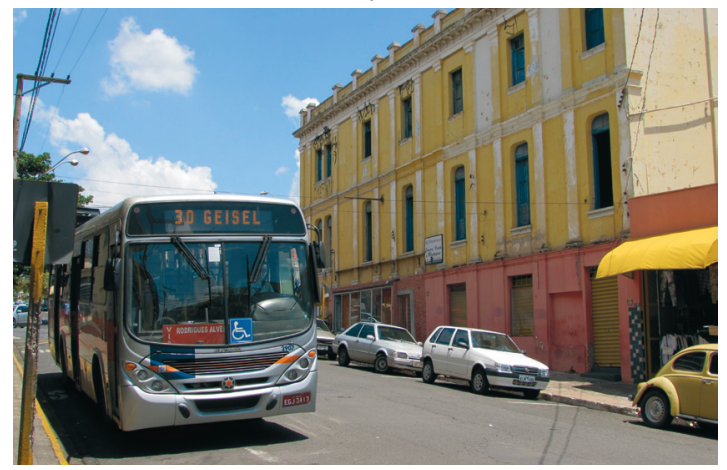

Fig. 6 - Tráfego intenso, Hotel Milanese (Sérgio Losnak, 19/08/2014).

Fig. 6 - Intense traffic, Hotel Milanese ((Sérgio Losnak, 19/08/2014).

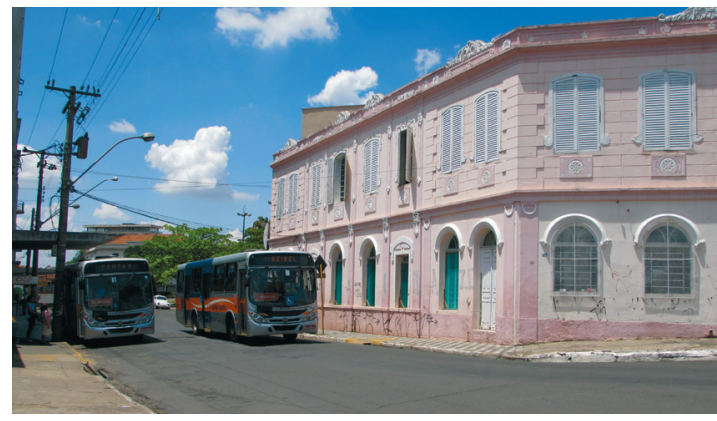

Fig. 7 - Tráfego intenso Hotel Cariani (Sérgio Losnak, 19/08/2014).

Fig. 7 - Intense traffic, Hotel Cariani (Sérgio Losnak, 19/08/2014).

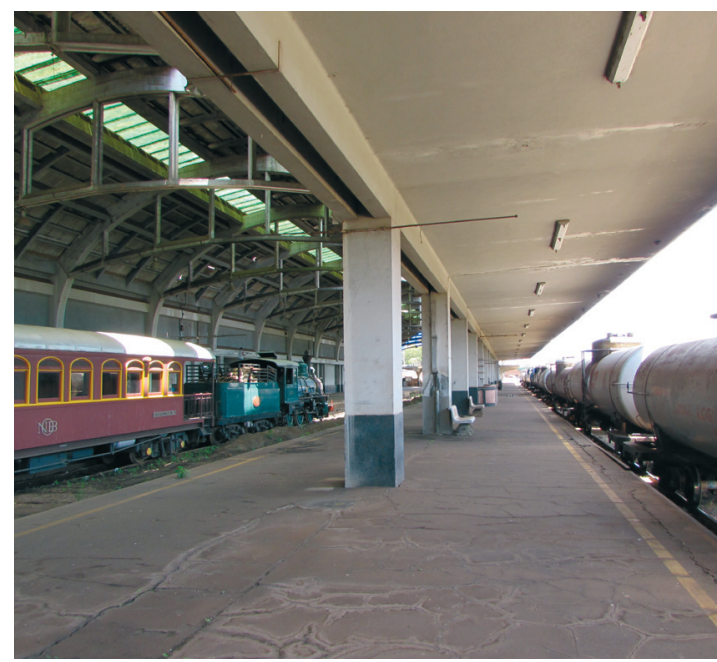

Fig. 8 - Tráfego interno de trens na Estação Estação Ferroviária da EFNOB (Sérgio Losnak, 19/08/2014).

Fig. 8 - Intense traffic of trains at the EFNOB Railway Station (Sérgio Losnak, 19/08/2014).

\section{Conclusões}

Com base nos resultados alcançados, pode-se concluir que:

- Diante da tipologia de agentes de riscos identificados que atuam na descaracterização dos patrimônios históricos, pode-se concluir que o fato de um bem estar tombado pelas instâncias competentes não garante a sua preservação;

- A desocupação, ocupação e os riscos aqui apontados, requerem de início a realização de inventário e um Plano de Gestão de Risco, que possa ser aplicado pelo município de modo a garantir a identidade cultural da cidade;

- Outra situação que causa determinada vulnerabilidade à integridade do bem é a falta de uma estrutura técnica específica que dê sustentação às ações do conselho. Torna-se necessário a formação de uma equipe multidisciplinar que realize sistematicamente estudos pertinentes aos bens e que possa estabelecer uma relação mais próxima com seus proprietários e usuários, oferecendo assessoria e formação no que se diz respeito à política de preservação e de prevenção de riscos no Município;

- Apesar da existência de regulamentações que tratam de importantes pontos que possam vir a garantir a salvaguarda do bem, na prática, a legislação não garante sua preservação. O método legal acaba provocando a precarização da posse e do próprio bem. $O$ ato de tombar se mostra insuficiente, criando uma dicotomia entre a preservação por ato oficial e a preservação de fato. 


\section{Referências Bibliográficas}

Amaro, Antônio (2003). Para uma cultura de riscos. Territorium, 10, Coimbra, p. 113-120. Disponível em: http://www.uc.pt/fluc/nicif/ riscos/Documentacao/Territorium/T10_artg/ T10_artg08.pdf.

Bauru, Prefeitura Municipal de (1997). Edição Histórica $81^{\circ}$ anos, Focus, Bauru.

Benévolo, Leonardo (1999). História da cidade, Perspectiva, São Paulo.

BRASIL. MINISTÉRIO DA CULTURA. INSTITUTO DO PATRIMÔNIO HISTÓRICO E ARTÍSTICO NACIONAL - IPHAN (2004). Cartas patrimoniais, IPHAN, Rio de Janeiro.

BRASIL. MINISTÉRIO DA CULTURA. INSTITUTO BRASILEIRO DE MUSEUS (2013). Programa para a gestão de riscos ao patrimônio Musealizado Brasileiro, IBRAM, Rio de Janeiro.

BRASIL. MINISTÉRIO DA CULTURA. INSTITUTO DO PATRIMÔNIO HISTÓRICO E ARTÍSTICO NACIONAL - IPHAN (2014). Tombamento. Disponível em: http://portal. iphan.gov.br/portal/montar PaginaSecao.do?i $\mathrm{d}=17738$ \&sigla=Institucional\&retorno=paginaln stitucional

Chaui, Marilena (2006). Cidadania cultural, O direito à cultura, Fundação Perceu Abramo, São Paulo.

CODEPAC: CONSELHO DE PROTEÇÃO AO PATRIMÔNIO CULTURAL (2014). Conselho de Defesa do Patrimônio Cultural de Bauru. Disponível em:http:// hotsite.bauru.sp.gov.br/codepac.

Claval, Paul (2007). A geografia cultural, 3. Ed, UFSC,Florianópolis.
Gil, Antônio Carlos (2002). Como elaborar projetos de pesquisa. 4. Ed, Atlas, São Paulo.

ICOMOS: CONSELHO INTERNACIONALDEMONUMENTOSESÍTIOS (1964). Carta de Veneza In: IPHAN - Cartas Patrimoniais. $3^{\text {a }}$ Ed, IPHAN, Rio de Janeiro, p. 91-95.

ICOMOS: CONSELHO INTERNACIONAL DE MONUMENTOS E SíTIOS (2003). Carta de Nizhny Tagil: Sobre el Patrimonio Industrial. Disponível em: http:// international.icomos.org/18thapril/2006/ nizhny-tagil-charter-sp.pdf

Junior, Durval Muniz de Albuquerque (2007). Fragmentos do Discurso Cultural: Por uma Análise Crítica do Discurso Sobre a Cultura no Brasil. Teorias \& Políticas Da Cultura - Visões Multidisciplinar, EDUFBA, Salvador.

Pesavento, Sandra Jatahy (2012). Cidade, espaço e tempo: reflexões sobre o patrimônio urbano no Brasil. Intervenções Urbanas na América Latina, SENAC, São Paulo.

Rubim, Antônio Albino Canelas (2007). Políticas culturais no Brasil: tristes tradições, enorme desafios. Políticas culturais no Brasil, EDUFBA, Salvador.

Sant 'agostinho, Lúcia Helena F (1995). Bauru, Chão de passagem: entreposto de valores na rota Atlântico - Pacífico (Disertação de Mestrado). FAU USP, São Paulo.

Silva, Alcides (1957). Roteiro Histórico: uma cidade e uma instituição, Tipografia Comercial, Bauru.

Zanirato, Silvia Helena (2010). Experiências de prevenção de riscos ao patrimônio cultural da humanidade. Revista Ambiente \& Sociedade, v. XIII, n. 1, jan-jun, UNICAMP, Campinas. 